\title{
Application of Promethee-Gaia Methodology in the Choice of Systems for Drying Paltry-Seeds and Powder Materials
}

\author{
Slavica Prvulovic - Dragisa Tolmac* - Ljiljana Radovanovic \\ University of Novi Sad, Technical Faculty "Mihajlo Pupin", Serbia
}

This work deals with the application of Promethee-Gaia methodology and the choice of three systems for drying paltry-seeds and powder materials pneumatic driers, spiral driers and rotation driers with a drum with regard to five different criteria. The analysis is based on the Promethee I method, the Promethee II method and the Promethee-Gaia method, which withal shows a complex figure of the relation between alternatives and criteria in the Gaia plane. In this work the application of Decision Lab program is shown, which was the basis in analysing results and ranking alternatives.

The paper analyzes three different systems for drying. When choosing the system of drying the comparative analysis of five influential parameters, such as: the coefficient of heat transfer, price, drying energy, thermal usefulness, specific use of energy. Based on the analysis, the application of a pneumatic dryer is the cheapest, given the significant savings in cost, ie. investment cost and energy efficient. Next in order of the spiral dryer, and third in the rotation with a drum dryer, in terms of benefits administration. (C) 2011 Journal of Mechanical Engineering. All rights reserved.

Keywords: method Promethee-Gaia, multi-criteria, systems for drying, Decision Lab program

\section{INTRODUCTION}

An analysis of decision problems shows philosophy which manage a sistematical and formal introduction to a desicion problem and offers practical approach to the problem. This is a way which uses its own set of logical methodologis and specification of a procedure which enables a sistematical analysis of a complex decision problem.

In the decision-making process atributes demonstrate characteristics of alternatives which we believe are relevant in our case. Alternatives are known beforehand, but atributes are always chosen and formulated alone.

The choice of attributes represents a considerable stage in the process of multi-criteria decision where the way is defined in terms of how the realization of appointment aims bare going to be followed. Due to this the schedule should be:

- complete and

- disconnect.

The ideal case in the choice between complicated alternatives is the choice between the dominating option, i.e. the apropos option which meets all the criteria and better in one atribute than in the another. But in practise this is not often the case. A well paid job means little free time. In other words, aims which we want to achieve are problematic so they cannot be realized at the same time.

Many methods of choice (which are suggested in literature principally in operation of exploration) can be placed into related groups which enable the ranking of offer alternatives or a choice between the best alternatives [1].

In the recent years several decision aid methods or decision support systems have been proposed to help in the selection of the best compromise alternatives. In this paper based on a short example, an overview of the PrometheeGaia methodology for treating multi-criteria problems [2] is given. This methodology is known not just as one of the most efficient ones but also one of the easiest in the field.

A particularly user-friendly software, called the Decision Lab has been developed in collaboration with a Canadian company Visual Decision to assist all kinds of decision-makers. Software Decision Lab [3], as a support at decision making was developed in cooperation with company Visual Decision, and is available to be used by individuals.

The Promethee-Gaia methodology is better than other methods of multiple criteria, as it, firstly, it provides a complete ranking 
of alternatives, from best to worst. At some other methods this is not the case, for example, the method of Elektra. Also, a clear graphical representation of alternatives and their values can be seen here and the decision maker does not have to go into the text part, which usually seems annoying. What distinguishes this particular methodology is the Gaia-plan alternatives and the criteria, which clearly show the best alternative, and the alternative for which criterion is the best.

\section{THE PROMETHEE METHOD}

The PROMETHEE method is a multicriteria decision-making method developed by Brans [3] and [4]. It is a ranking method quite simple in conception and application compared to other methods for multi-criteria analysis. It is well adapted to problems where a finite number of alternative actions are to be ranked considering several, sometimes conflicting, criteria [5] and [6].

The PROMETHEE method is appropriate to treat the multi-criteria problem of the following type:

$$
\max \left\{f_{1}(a), \ldots, f_{n}(a) \mid a \backslash A\right\},
$$

where $A$ is a finite set of possible alternatives, and $f_{j}$ are $n$ criteria to be maximized. For each alternative, $f_{j}(a)$ is an evaluation of this alternative. When we compare two alternatives $a$, $b \backslash A$, we must be able to express the result of these comparisons in terms of preference. We, therefore, consider a preference function $P$. Let

$$
\begin{gathered}
P(a, b)=F(d)=F[f(a)-f(b)], \\
0 \leq P(a, b) \leq 1,
\end{gathered}
$$

be the preference function associated to the criteria, where $F(d)$ is a monotonically increasing function of the observed deviation (d) between $f(a)$ and $f(b)$. In order to facilitate the selection of specific preference function, six basic types of this preference function are proposed to the decision maker, in each case no more than two parameters (thresholds $q, p$ or $s$ ) have to be fixed [5] and [7].

Indifference threshold $q$ : the largest deviation to consider as negligible on that criterion. It is a small value with respect to the scale of measurement.

Preference threshold $p$ : the smallest deviation to consider as decisive in the preference of one alternative over another. It is a large value with respect to the scale of measurement.

Gaussian threshold $s$ : it is only used with the Gaussian preference function. It is usually fixed as an intermediate value between an indifference and a preference threshold.

Promethee permits the computation of the following quantities for alternatives $a$ and $b$ :

$a$ and $b$ are alternatives from the first set of alternatives $A$. Then is:

$$
\begin{aligned}
& \pi(a, b)=\sum_{j=1}^{k} P_{j}(a, b) w_{j}, \\
& \pi(b, a)=\sum_{j=1}^{k} P_{j}(b, a) w_{j},
\end{aligned}
$$

- positive course of preferential (output course):

$$
\Phi^{+}(a)=\frac{1}{n-1} \sum_{x \in A} \pi(a, x)
$$

- $\quad$ negative course of preferential (input course):

$$
\Phi^{-}(a)=\frac{1}{n-1} \sum_{x \in A} \pi(x, a),
$$

where $w_{j}$ are weights associated with criteria.

For each alternative $a$, belonging to the set $A$ of alternatives, $\pi(a, b)$ is an overall preference index of $a$ over $b$. The leaving flow $\Phi^{+}(a)$ is the measure of the outranking character of $a$ (how $a$ dominates all the other alternatives of $A$ ). Symmetrically, the entering flow $\Phi^{-}(a)$ gives the outranked character of $a$ (how $a$ is dominated by all the other alternatives of $A)$. $\Phi(a)$ represents a value function, whereby a higher value reflects a higher attractiveness of alternative $a . \Phi(a)$ is called the net flow of alternative $a$ [8]. All the alternatives can be completely ranked (Promethee II) by net flow.

The geometrical analysis for interactive aid (Gaia) plane displays graphically the relative position of the alternatives in terms of contributions to the various criteria [8] and [9].

\subsection{The Promethee \& Gaia Analysis}

The purpose of this paper is not to explain in details the Promethee methodology. See for instance Brans [3] and [8]. Only the results 
provided by the Decision Lab software on the above-mentioned example [10].

Promethee requests additional information. For each criterion a specific preference function must be defined. This function is used to compute the degree of preference associated to the best action in case of pair wise comparisons [11] and [12]. Six possible shapes of preference functions are available in the software (Table 2). These are described for instance in Brans [8]. In this example, the shapes 5 (linear), 3 (V-shape), 2 (U-shape), 6 (Gaussian) and 1 (usual) have been respectively associated to the five criteria.

Promethee \& Gaia calculate positive and negative preference flows for each alternative [8]. The positive flow expresses how much an alternative is dominating (power) the other ones, and the negative flow how much it is a dominated (weakness) by the other ones. Based on these flows, the Promethee I, partial ranking is obtained, Fig. 1.

\subsection{The Decision Lab 2000 Software}

The Decision Lab 2000 software is an up-to-date implementation of the Promethee \& Gaia methods [13] and [14]. It includes many practical developments, such as the treatment of missing values, the definition of categories of actions or criteria, as well as a powerful group decision extensions through the definition of multiple scenarios [4], [15] and [16]. The Canadian company Visual Decision develops decision Lab. It works under Windows 95, 98, NT or 2000 on PC compatible microcomputers will be commented on. A demo version as well as full versions (Executive or Developer - including programming capabilities) is available from Visual Decision (http://www.visualdecision.com).

\section{APPLICATION OF THE PROMETHEE METHOD IN THE CHOICE OF THE SYSTEM FOR DRYING CORN STARCH, RESULTS AND DISCUSSION}

In this work a choice has been made of the most effective driers between the three which are offered and pointed with $a_{i}$ on the base of five criterium pointed with $f_{j}$.

Offered alternatives $a_{i}$ :

$a_{1}$ - pneumatic dryer,

$a_{2}$ - spiral dryer,

$a_{3}$ - rotation dryer with a drum.

Offered characteristic (criterion) $\left(f_{j}\right)$ :

$f_{1}$ - coefficient of heat transfer $\left[\mathrm{W} / \mathrm{m}^{2} \mathrm{~K}\right]$,

$f_{2}-$ price $[€]$,

$f_{3}$ - drying energy $[\mathrm{kW}]$,

$f_{4}$ - termic useful degree [\%],

$f_{5}-$ specific use of energy $[\mathrm{kJ} / \mathrm{kg}]$.

For each of the criteria responsive weights

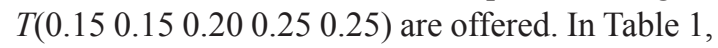
systems for drying which are ranked on the base of offered criteria, are shown. Such dryer systems are introduced in literature [17] and [18] and [19] and [20].

Definition type, parameters and weight coefficient:

The person who makes a decision resolves problems, defines types of general criteria, parametres and weight useful criteria apropos each criterion is given an analogous function of preferention [1].

In this case, the person who makes a decision is decided next, Table 2 .

Determinate input $\left(\Phi^{+}\right)$, output $\left(\Phi^{-}\right)$and a clean course of preferention .

Table 1. System characteristics for drying corn starch

\begin{tabular}{|l|c|c|c|c|c|}
\hline & $\begin{array}{c}\text { Coefficient of } \\
\text { heat transfer } \\
{\left[\mathrm{W} / \mathrm{m}^{2} \mathrm{~K}\right]}\end{array}$ & $\begin{array}{c}\text { Price } \\
{[€]}\end{array}$ & $\begin{array}{c}\text { Drying energy } \\
{[\mathrm{kW}]}\end{array}$ & $\begin{array}{c}\text { Termic useful } \\
\text { degree } \\
{[\%]}\end{array}$ & $\begin{array}{c}\text { Specific use } \\
\text { of energy } \\
{[\mathrm{kJ} / \mathrm{kg}]}\end{array}$ \\
\cline { 2 - 6 } & $\max$ & $\min$ & $\max$ & $\max$ & $\min$ \\
\hline Pneumatic dryer & 295 & 673500 & 2215 & 66 & 3710 \\
\hline Spiral dryer & 308 & 555000 & 1850 & 52 & 3056 \\
\hline $\begin{array}{l}\text { Rotation dryer } \\
\text { with a drum }\end{array}$ & 195 & 753000 & 2510 & 54 & 4150 \\
\hline Weight coefficient & 0.15 & 0.15 & 0.20 & 0.25 & 0.25 \\
\hline
\end{tabular}


Table 2. Award function of preferention, responsive parametres and weights

\begin{tabular}{|c|c|c|c|c|c|}
\hline & $f_{1}$ & $f_{2}$ & $f_{3}$ & $\mathrm{f}_{4}$ & $f_{5}$ \\
\hline Type & III & $\mathrm{V}$ & $\mathrm{I}$ & $\mathrm{IV}$ & $\mathrm{I}$ \\
\hline$m$ & - & 0.2 & - & 1.0 & - \\
\hline$n$ & 2.5 & 0.5 & - & 2.0 & - \\
\hline$t$ & 0.15 & 0.15 & 0.20 & 0.25 & 0.25 \\
\hline
\end{tabular}

To determine the input course action the Eq (8) [4] is used:

$$
\Phi^{+}(a)=\sum_{x \in A} I P(a, x) \text { or } \Phi^{+}(a)=\frac{\sum_{x \in A} I P(a, x)}{i-1} .
$$

To determine the output course action the

expression is used:
$\Phi^{-}(a)=\sum_{x \in A} I P(x, a)$ or $\Phi^{-}(a)=\frac{\sum_{x \in A} I P(x, a)}{i-1}$.

The obtained results are shown in Table 3, according to [8] and [10].

Table 3. Input, output and clean course of preferention

\begin{tabular}{|c|c|c|c|}
\hline & $\Phi+$ & $\Phi-$ & $\Phi$ \\
\hline Pneumatic dryer & 0.6250 & 0.3750 & 0.2500 \\
\hline $\begin{array}{c}\text { Rotation dryer } \\
\text { with a drum }\end{array}$ & 0.2625 & 0.6750 & -0.4125 \\
\hline
\end{tabular}

Ranking action on the base of the weight clean course. On the other hand, the Promethean II provides a complete ranking, Fig. 2. It is based on the balance of the two preference flows. The information looks more reliable but some part of it gets lost in the process. Both Promethean I and II help the decision-maker to finalize the selection of the best compromise. A clear view of the outranking relations between the alternatives is obtained.

It is clear the Promethee I and II rankings are influenced by the weights allocated to the criteria. A special feature of the software, called The Walking Weights, Fig. 3, allows to modify the weights and to observe the resulting modifications of the Promethee II ranking. For the following weight distribution [21] to [23] it can be easily observed that pneumatic driers still dominates the other ones. It is a position, as the best compromise, which seems to be very stable. On the other hand, the ranking of the last five actions is now completely opposite. Such a sensitivity analysis tool is particularly valuable when the decisionmaker has no predetermined weights in mind.

The information relative to a decision problem including $k$ criteria can be represented in a $k$-dimensional space. The GAIA plane is obtained by projection of this information on a plane such that as few information as possible get lost. Points and criteria represent alternatives. The conflicting character of the criteria appears clearly, in Fig.

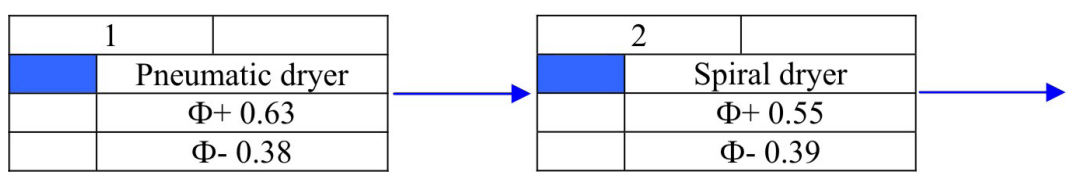

Fig. 1. Promethee I ranking

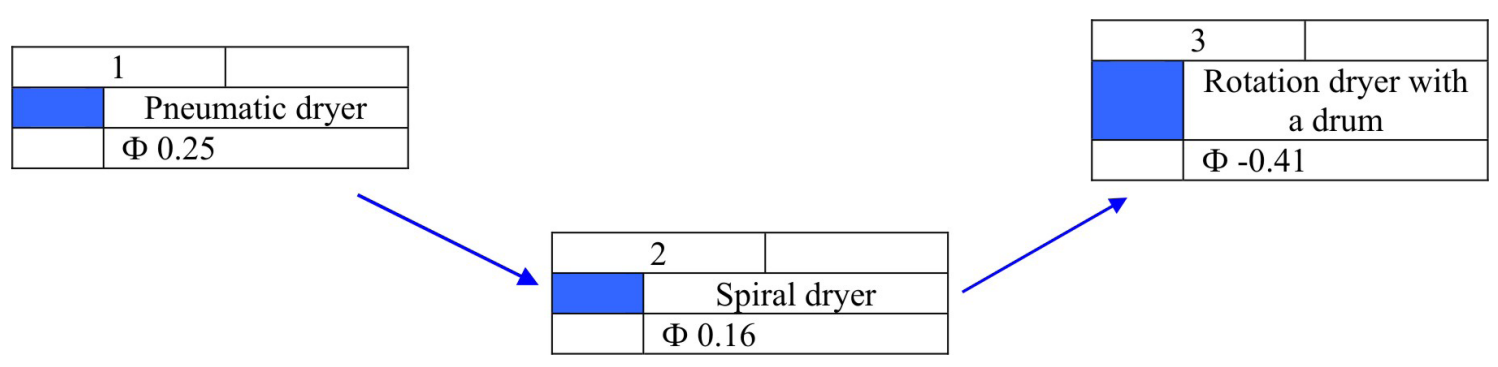

Fig. 2. Promethee II ranking 


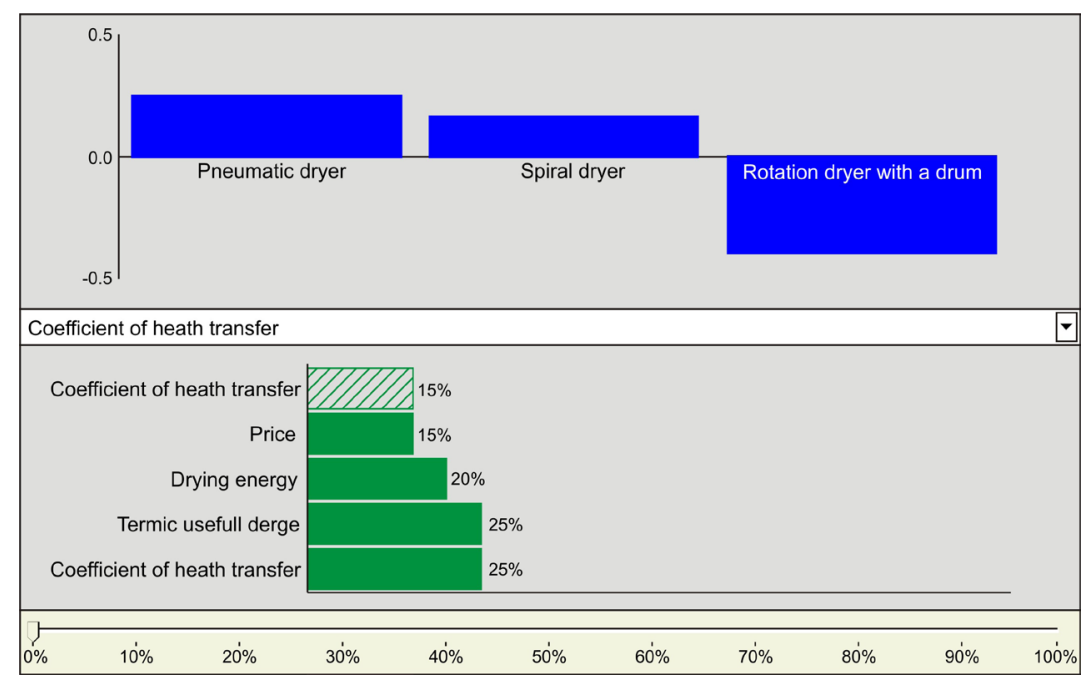

Fig. 3. Walking Weight-option which is used to make sensible score analysis

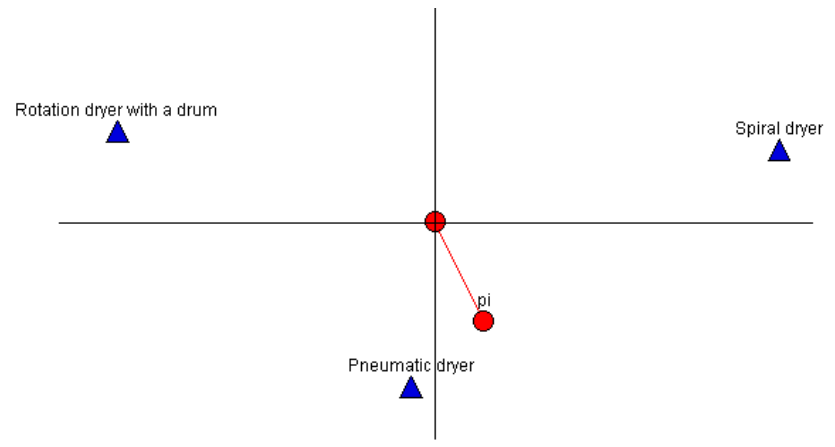

Fig. 4. GAIA plane for afford decide problem (activity plane dryer)

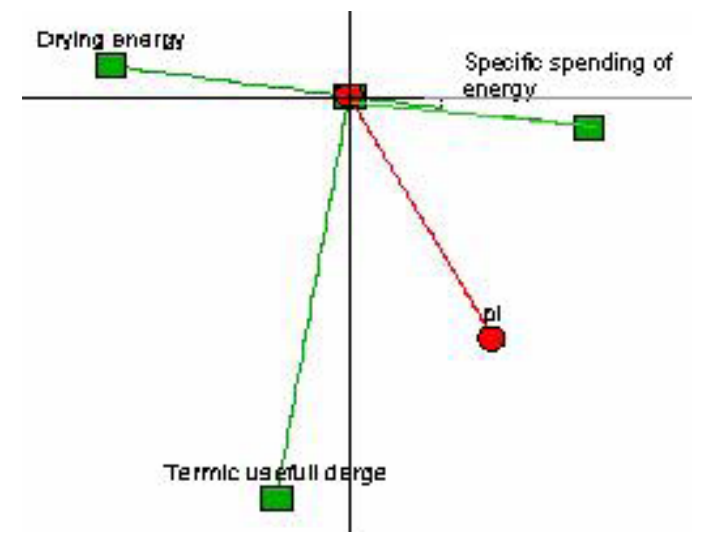

Fig. 5. GAIA plane for afford deciding problem (criterion plane dryer)

4 , and the criteria expressing similar preferences of the data point to the same direction, while conflicting criteria point in opposite directions.
In addition to the representation of the alternatives and criteria, the projection of the weight vector in the GAIA plane which corresponds to another axis ( $\pi$, the Promethee 
decision axis) that shows the direction of the compromise resulting from the weights allocated to the criteria. The decision-maker is invited to consider the alternatives located in that direction. When the weights are modified, the positions of the alternatives and the criteria remain the same, and only the decision axis $\pi$ is changing [8]. The software allows using the weights vector as a decision stick to orientate the decision. The movements of the stick corresponding to modifications of the weights are directly displayed in the 3D-view window of the GAIA screen, Figs. 4 and 5 . When the decision-maker is not able or does not want to allocate precise weights to the criteria, it is possible to specify intervals of possible values rather than one fixed value for each weight. In this case, the Promethee VI procedure can be used to indicate whether the problem is soft or hard. It is soft when the decision axis $\pi$ always remains in the same general direction for the weight distributions that are compatible with the intervals. It is hard when the opposite direction is possible depending on the actual values of the weights. In case of a difficult problem, the decision-maker should concentrate on more precise values of the weights. This feature is currently not implemented in the Decision Lab. With regard to the Gaia plane, a conclusion can be made that the best alternative is the pneumatic drier, having the $\pi$ vector in its plane. It is best regarding the thermal exploitation level criteria. The rotation dryer is the best regarding heat energy criteria, whereas the spiral dryer is the best regarding criteria of heat transfer, price and specific energy consumption, whose vectors overlap.

\section{CONCLUSION}

It can be concluded that in this work a multi-criteria analysis of three systems for drying has been done, on the base of five criteria which were helped with Promethee, and with the application of responsive software [8], which enabled easy work, a faster finishing date and enabled faster choice appropriate drying. The final result was achieved in a few steps and it began from the base jig with her alternatives and criteria and finished with a definitive choice, apropos ranking. Based on ranking, a definitive choice between the best drying, apropos the best solution at all the criteria is the choice of pneumatic dryers and which can be clearly seen in the Figs. 1 to 5, where it is shown that alternative $a_{1}$ (pneumatic dryers) has dominated above alternatives $a_{2}$ (spiral dryers) and $a_{3}$ (rotation dryers with a drum).

\section{REFERENCES}

[1] Aubert, B.A., Riverd, S., Patry, M. (2004). A transaction cost model of IT outsourcing. Information \& Management, vol. 41, p. 921932.

[2] Goumas, M., Lygerou, V. (2000). An extension of the Promethee method for decision making in fuzzy environment: ranking of alternative energy exploitation. European Journal of Operational Research, vol. 123, p. 606-613.

[3] Brans, J.P., Mareschal, B. (1992). Promethee $\mathrm{V}$ : MCDM problems with additional segmentation constraints. INFOR, vol. 30, no. 2, p. 85-96.

[4] Macharis, C., Springael, J., De Brucher, K., Verbeke, A. (2004). Promethee and AHP: the design of operational synergies in multicriteria analysis. Strengthening PROMETHEE with ideas of AHP. European Journal of Operational Research, vol. 153, no. 2, p. 307-317.

[5] Climaco, J. (1997). Multicriteria Analysis. Springer-Verlag, New York.

[6] De Smet, Y., Mareschal, B., Verly. C. (2009). Extending the Promethee II method to continuous and combinatorial multiobjective optimization problems: a first model. IEEE International Conference on Industrial Engineering and Engineering Management, vol. 1-4, p. 1608-1611.

[7] Ketler, K., Walstrom, J. (1993). The outsourcing decision. International Journal of Information Management, vol. 13, p. 449459.

[8] Brans, J.P., Marechal, B. (1994). The PROMCALC \& GAIA decision support system for multicriteria decision aid. Decision Support Systems, vol. 12, p. 297310.

[9] Collins, J., Millen, R., Beamish, P. (1995). Information systems outsourcing by large American industrial firms: choice and 
impact. Information Resources Management Journal, vol. 8, no. 1, p. 5-13.

[10] Lacity, M.C., Willcock, L. (1998). An empirical investigation of information technology sourcing practices, Lessons from experience. MIS Quarterly, vol. 22, no. 3, p. 363-408.

[11] Costa, A.P.C.S., De Almeida, A.T. (2002). Promethee multicriteria aid on priorities assignment of information systems. IEEE International Conference on Systems, Man and Cybernetics, Conference Proceedings, p. 1913-1917.

[12] Hsu, C.I, Chiu, C., Hsu, P.L. (2004). Predicting information systems outsourcing success using a hierarchical design of case-based reasoning. Expert Systems with Applications, vol. 26, no. 3, p. 435-441.

[13] Mareschal, B., De Smet, Y. (2009). Visual Promethee: Developments of the Promethee \& GAIA multicriteria decision aid methods. IEEE International Conference on Industrial Engineering and Engineering Management, vol. 1-4, p. 1646-1649.

[14] Ocelikova, E., Klimesova, D. (2010). Using Promethee method for the ranking of multidimensional data. $8^{\text {th }}$ International Symposium on Applied Machine Intelligence and Informatics, p. 93-96.

[15] Potvin, J.Y., Soriano, P., Vallee, M. (2004). Generating trading rules on the stock markets with genetic programming. Computers and Operations Research, vol. 31, no. 7, p. 1033-1047.

[16] Yang, C., Huang, J. (2000). A decision model for IS outsourcing. International Journal of
Information Management, vol. 20, no. 3, p. 225-239.

[17] Prvulovic, S., Tolmac, D., Lambic, M., Radovanovic, L. (2007). Efects of heat transfer in a horizontal rotating cyilinder of the contact dryer. Facta Universitatis, vol. 5, no. 1, p. 47-61.

[18] Prvulovic, S., Tolmac, D., Lambic, M. (2007). Convection Drying in the Food Industry. Agricultural Engineering International the CIGR Ejournal, vol. 9, no. 9, p. 1-12.

[19] Tolmac, D., Lambic, M. (1997). Heat transfer through rotating roll of contact dryer. International Communications in Heat and Mass Transfer, vol. 24, p. 569573.

[20] Tolmac, D., Prvulovic, S., Lambic, M. (2007). The mathematical model of the heat transfer for the contact dryer. FME Transactions, vol. 35, no. 1, p. 15-22.

[21] Grover, V., Joong, M., Cheon, T. (1996). The effect of service qualify and partnership on the outsourcing of information systems functions. Journal of Management Information Systems, vol. 12, no. 4, p. 89116.

[22] King, W.R. (2001). Developing a sourcing strategy for IS: a behavioral decision process and framework. IEEE Transactions on Engineering Management, vol. 48, no. 1, p. 15-24.

[23] Prvulovic, S., Tolmac, D., Radovanovic, L. (2008). Researching results energetics characteristics convection drying. Strojniški vestnik-Journal of Mechanical Engineering, vol. 54, no. 9, p. 639-644. 